\title{
OPEN Microwave-assisted enzymatic hydrolysis to produce xylooligosaccharides from rice husk alkali-soluble arabinoxylan
}

\author{
Wannaporn Klangpetch ${ }^{1,2,3 \bowtie}$, Alisa Pattarapisitporn ${ }^{4}$, Suphat Phongthai ${ }^{1,5}$, \\ Niramon Utama-ang ${ }^{1,2,3}$, Thunnop Laokuldilok ${ }^{1,2,3}$, Pipat Tangjaidee ${ }^{1,3}$, \\ Tri Indrarini Wirjantoro, ${ }^{1,3}$ \& Pannapapol Jaichakan ${ }^{6}$
}

The prebiotic properties of xylooligosaccharides (XOS) and arabino-xylooligosaccharides (AXOS) produced from rice husk $(\mathrm{RH})$ using microwave treatment combined with enzymatic hydrolysis were evaluated. The $\mathrm{RH}$ was subjected to microwave pretreatment at 140,160 and $180^{\circ} \mathrm{C}$ for 5,10 and $15 \mathrm{~min}$ to obtain crude arabinoxylan (AX). Increasing microwave pretreatment time increased sugar content. Crude AX was extracted with $2 \%(w / v)$ sodium hydroxide at $25^{\circ} \mathrm{C}$ for $24 \mathrm{~h}$ and used as a substrate for XOS production by commercial xylanases. Results showed that oligosaccharides produced by Pentopan Mono BG and Ultraflo Max provided xylobiose and xylotriose as the main products. AXOS was also present in the oligosaccharides that promoted growth of Lactobacillus spp. and resisted degradation by over $70 \%$ after exposure to simulated human digestion.

The rice husk $(\mathrm{RH})$ acts as a sheath to protect the rice seed during the growth period. The rice milling process generates approximately $28 \%$ of $\mathrm{RH}$ as a by-product that is mostly used as a solid fuel. Previous studies reported that RH contains lignocellulosic material that consists of cellulose and hemicellulose at 36\% and 29\%, respectively ${ }^{1}$. The hemicellulose structure of RH contains long-chain xylose units as the backbone, called xylan. Xylan comprises a group of hemicelluloses, that are composed of $\beta$-1,4-linked xylose residues with or without side branches of acetyl groups, arabinose, glucuronic acid and 4-O-methyl glucuronic acid $^{2}$. Arabinoxylans (AX) are one of the four types of xylans, that have a backbone of $\beta$-(1,4)-linked xylose residues, substituted with arabinose residues at the $\mathrm{C}(\mathrm{O})-2$ and/or $\mathrm{C}(\mathrm{O})-3$ positions ${ }^{3}$.

Conversion of AX by enzymatic hydrolysis into xylooligosaccharides (XOS) and arabino-xylooligosaccharides (AXOS) has gained considerable interest because of the mild conditions used and the specific products obtained. XOS have more effective properties than other oligosaccharides. Recent reports indicated that fermentation of XOS by L. brevis S27, L. pentosus S42 and L. plantarum S61, with enhanced antifungal and antibacterial activities compared to fructo-oligosaccharides (FOS) ${ }^{4}$. The effective daily dose of oligosaccharides indicating that XOS has a greater range of health benefits than FOS and inulin at a lower dose ${ }^{5}$. XOS are also the only nutraceutical that can be obtained from lignocellulosic biomass as a low-cost and abundantly available raw material ${ }^{6}$. XOS are non-digestible food ingredients with prebiotic properties for selectively promoting the growth of probiotics, thereby providing many health benefits and several applications on food and pharmaceutical industries ${ }^{7}$. Growth of Bifidobacterium breve, B. lactis, B. adolescentis, and B. bifidum has been demonstrated to ferment XOS in vitro and in vivo ${ }^{8}$. Production of XOS and AXOS is usually performed by endo-1,4- $\beta$-D-xylanase (EC 3.2.1.8), which is the major enzyme involved in the breakdown of $\beta$-1,4-linked xylan into XOS of varying lengths and has tolerance for arabinose substitutions in the xylan chain ${ }^{9}$. The activities of exo-1,4-xylosidase (EC 3.2.1.37) and exo-1,3-xylosidase (EC 3.2.1.72) are key in the hydrolysis of xylan to xylose ${ }^{10}$. Xylanases with different activities and substrate specificities produce various end products in enzymatic hydrolysis ${ }^{11}$. This research focused

\footnotetext{
${ }^{1}$ Faculty of Agro-Industry, Chiang Mai University, Chiang Mai 50100, Thailand. ${ }^{2}$ Cluster of High Value Products from Thai Rice and Plants for Health, Chiang Mai University, Chiang Mai 50100, Thailand. ${ }^{3}$ Cluster of Innovative Food and Agro-Industry, Chiang Mai University, Chiang Mai 50100, Thailand. ${ }^{4}$ Graduate School of Agriculture, Saga University, Honjo, Saga 840-8502, Japan. ${ }^{5}$ Research Center for Development of Local Lanna Rice and Rice Products, Chiang Mai University, Chiang Mai 50200, Thailand. ${ }^{6}$ Department of Agro-Industry, Faculty of Agriculture Natural Resources and Environment, Naresuan University, Phitsanulok 65000, Thailand. ${ }^{凶}$ email: wannaporn.u@ cmu.ac.th
} 
on two xylanases belonging to the glycoside hydrolase families 10 and 11 . GH11 xylanases preferentially cleave unsubstituted regions of the AX backbone and whereas GH10 enzymes are less hampered by the presence of substituents along the xylan backbone, cleave the decorated regions ${ }^{12}$. Therefore, differences in substrate specificity have important implications in the deconstruction of xylan in biomass ${ }^{13}$.

Recently, many techniques have been applied for AX extraction. Fermentation or solvent extraction can reduce the loss of important substances compared to the heating process. Acid detergent fiber, neutral detergent fiber, hemicellulose, and crude cellulose of lignocelluloses were lost in biomass treated with fungal fermentation ${ }^{14}$. However, these methods are time-consuming and produce various chemical wastes. Microwave extraction may overcome these disadvantages with short processing time and low amount of solvent utilization ${ }^{15}$. Microwave pretreatment is a promising technology for biomass conversion, with efficiency dependent on the dielectric properties of the biomass and solvent, allowing the material to be retained. The electromagnetic power is converted into heat, causing lignocellulosic material breakdown via molecular collision due to dielectric polarization ${ }^{16,17}$. Other heating processes such as hydrothermal treatment using high temperatures for a longer time, result in the loss of important substances including large amounts of monosaccharides. Gissibl et al. ${ }^{18}$ recently revealed that microwave pretreatment at $170{ }^{\circ} \mathrm{C}$ for 2 min enhanced enzymatic production of soluble $\beta$-1,3-glucans, while microwave treatment at $200{ }^{\circ} \mathrm{C}$ for 5 min significantly increased oligosaccharide extraction yield from spruce wood $^{19}$. Coelho et al. ${ }^{20}$ reported that microwave superheated water at $210{ }^{\circ} \mathrm{C}$ with dilute alkali recovered $43 \%$ of AX and AXOS from spent grain after the brewing process, while Kundu et al. ${ }^{21}$ stated that cleavage of alkalilabile linkages between hemicellulose and other associated constituents depended on its natural performance.

A prebiotic can be defined as "a substrate that is selectively utilized by host microorganisms conferring a health benefit. This definition expands the concept of prebiotics to possibly include non-carbohydrate substances, applications to body sites other than the gastrointestinal tract, and diverse categories other than food" (Gibson et al., 2017). AX can be transformed into XOS and AXOS that are considered to be functional foods due to their potential prebiotic properties. XOS and AXOS enter the colon intact and serve as carbon sources for bacteria including Bifidobacterium and Lactobacillus ${ }^{22}$. Probiotic fermentation assists the development of short-chain fatty acids such as acetate, propionate and butyrate, which provide the host with metabolic energy and intestinal acidification $^{23}$.

This study investigated the effects of temperature and microwave pretreatment time on RH-derived AX extraction to produce XOS and AXOS by GH10 and GH11 xylanases. The growth promotion of lactic acid bacteria and digestion resistance were evaluated using an in vitro human digestion simulation to demonstrate the prebiotic potential of XOS and AXOS. This research will maximize the use of rice husk by-product as an alternative prebiotic source.

\section{Materials and methods}

Materials. Rice husk (RH) was kindly provided by a local rice milling plant in Phitsanulok Province, Thailand. The RH was dried in a hot-air oven at $40{ }^{\circ} \mathrm{C}$ until the moisture content was lower than $10 \%(\mathrm{w} / \mathrm{w})$, then crushed with a blender and sieved through a $40 \mu \mathrm{m}$ mesh screen. RH powder was stored in a zip lock bag at $30{ }^{\circ} \mathrm{C}$. The method of the Association of Official Analytical Chemists was used for determination of moisture, crude fiber, protein, fat, ash and carbohydrate of $\mathrm{RH}^{24}$.

Commercial xylanases as Ultraflo Max $(700 \mathrm{U} / \mathrm{mL}$ from Aspergillus oryzae and Trichoderma reesei) and Pentopan Mono BG (2,500 U/g from Thermomyces lanuginosus) were purchased from Novozyme Co., Ltd., Denmark. All chemicals and solvents were of analytical grade. Xylose (Merck, Germany), arabinose (Sigma, Germany), mannose (Merck, Germany), galactose (Sigma, Germany) and glucose (Sigma, Germany) were used as standards for determination of carbohydrate composition. A mixture of arabinose (A1) (Sigma, USA), xylose (X1) (Merck, Germany), xylobiose (X2), xylotriose (X3), xylotetraose (X4), xylopentaose (X5), xylohexaose (X6), (Wako, Japan), $2^{3}$ - $\alpha$-L-arabinofuranosyl-xylotriose (A2XX), $3^{2}$ - $\alpha$-L-arabinofuranosyl-xylobiose (A3X), $3^{3}$ - $\alpha$-L-arabinofuranosyl-xylotetraose (XA3XX) and $2^{3}, 3^{3}$-di- $\alpha$-L-arabinofuranosyl-xylotriose (A2,3XX) (Megazyme, Ireland) were used as standards for the determination of oligosaccharides. Commercial prebiotics were used to compare prebiotic properties with the obtained oligosaccharides. A 95\% commercial XOS (XOS95P) was purchased from AWBIO, Taiwan, while resistant maltodextrin (RMD) and inulin were purchased from Blenntag Ingredients, Thailand. Simulated human digestion enzymes, $\alpha$-amylase from $A$. oryzae $(40,000 \mathrm{U} / \mathrm{mL})$, pepsin from porcine gastric mucosa $(3200 \mathrm{U} / \mathrm{mg}$ ) and pancreatin from porcine pancreas (8X USP) (Sigma, Germany) were used as simulated human digestion enzymes.

Pretreatment of RH. One gram of previously prepared $\mathrm{RH}$ powder was soaked in $20 \mathrm{~mL}$ of acetone and ethanol mixture in the ratio of $1: 2(\mathrm{v} / \mathrm{v})$ at $30^{\circ} \mathrm{C}$ for $24 \mathrm{~h}$. The $\mathrm{RH}$ residue was filtered through Whatman No. 1 filter paper and washed with boiling water. After rewashing with distilled water, the residue was dried at $45^{\circ} \mathrm{C}$ for $24 \mathrm{~h}$ in a hot air oven to obtain extractive-free $\mathrm{RH}$, and used in microwave pretreatment.

Determination of carbohydrate composition. The determination methods for structural carbohydrates of RH and extractive-free $\mathrm{RH}$ were modified from Jaichakan et al. ${ }^{25}$. Briefly, $0.4 \mathrm{~g}$ of extractive-free $\mathrm{RH}$ was pre-hydrolysed with $4.5 \mathrm{~mL}$ of $72 \%$ sulfuric acid and mixed for $30 \mathrm{~min}$ in a mortar. Upon completion of pre-hydrolysis, the slurry was diluted to a final acid concentration of $4 \%$ by adding $84 \mathrm{~mL}$ distilled water and autoclaved for $1 \mathrm{~h}$ at $121^{\circ} \mathrm{C}$. After completion of the autoclave cycle, a $10 \mathrm{~mL}$ aliquot was transferred and neutralized to $\mathrm{pH}$ 5-6 with calcium carbonate. This aliquot was used to determine structural carbohydrates by high-performance anion exchange chromatography with pulsed amperometric detection (HPAEC-PAD, Dionex ICS-5000 Ion Chromatography, Thermo Scientific, Bellefonte PA, USA) with a Dionex CarboPac PA-1 column $(250 \mathrm{~mm} \times 4 \mathrm{~mm})$ and a guard column $(50 \mathrm{~mm} \times 4 \mathrm{~mm})$ with an injection volume of $20 \mu \mathrm{L}$ and a flow rate of 
$1.0 \mathrm{~mL} / \mathrm{min}$. The post-column pump operated at a flow rate of $0.5 \mathrm{~mL} / \mathrm{min}$ with $300 \mathrm{mM}$ sodium hydroxide. A stepwise linear gradient was applied over 20 min with $100 \%$ distilled water and applied over 16 min by mixing solutions of $200 \mathrm{mM}$ sodium hydroxide and $200 \mathrm{mM}$ sodium acetate in $170 \mathrm{mM}$ sodium acetate. Eluted monosaccharides were monitored by PAD detection using a gold electrode. A mixture of xylose, arabinose, mannose, galactose, and glucose was utilized at a concentration range of $0-5 \mathrm{ppm}$ as a calibration standard.

Carbohydrate profiles of oligosaccharides produced from RH were determined by HPAEC with a Dionex CarboPac PA-200 column $(250 \mathrm{~mm} \times 4 \mathrm{~mm})$ and a guard column $(50 \mathrm{~mm} \times 4 \mathrm{~mm})$ with an injection volume of $20 \mu \mathrm{L}$ and constant flow rate of $0.4 \mathrm{~mL} / \mathrm{min}$. The gradient elution program for the sample pump of the neutral carbohydrate was performed as described by McCleary et al. ${ }^{26}$. Oligosaccharides were identified using A1, X1-X6, $\mathrm{A} 2 \mathrm{XX}, \mathrm{A} 3 \mathrm{X}, \mathrm{XA} 3 \mathrm{XX}$ and $\mathrm{A} 2,3 \mathrm{XX}$ at a concentration range of $0-5 \mathrm{ppm}$ as standards.

The polymeric sugars were calculated from the concentration of the corresponding monomeric sugars according to the National Renewable Energy Laboratory. For C-5 sugars (xylose and arabinose), an anhydro correction factor of 0.88 was used, with 0.90 for C- 6 sugars (glucose, galactose and mannose) ${ }^{27}$.

Polymeric sugar $=$ monomeric sugar content $\times$ Anhydro correction

Microwave pretreatment of extractive-free RH. A closed-vessel microwave digestion system equipped with a 10 position rotor and capable of delivering $1600 \mathrm{~W}$ of power (ETHOS 1600, Milestone Inc., Sorisole, Italy) was used for sample pretreatment. The temperature of all samples was directly controlled by this easyTEMP contactless sensor, using a high-pressure and high-temperature rotor (SK-15 easyTEMP high pressure rotor, Milestone Inc., Sorisole, Italy) with a capacity of up to 15 vessels. Vessels used with this machine were made of modified polytetrafluoroethylene (PTFE) with $100 \mathrm{~mL}$ volume. Each vessel contained $45 \mathrm{~mL}$ of sample. During each run, 15 vessels were fitted in all positions. An aliquot of $1.5 \mathrm{~g}$ of the extractive-free $\mathrm{RH}$ was suspended in $45 \mathrm{~mL}$ of distilled water in the PTFE closed vessel. The heating program was performed at microwave irradiation power of 600,1100 and $1600 \mathrm{~W}$ to reach 140,160 and $180^{\circ} \mathrm{C}$, respectively in 5 min (come up time), and then held for predetermined times of 5, 10 and $15 \mathrm{~min}$ for each temperature. Temperature and pressure sensors were used in all treatments. After completion, the reactant was immediately cooled to $25^{\circ} \mathrm{C}$ in a cold water bath. Microwave-pretreated residues were separated by vacuum filtration. The pretreated $\mathrm{RH}$ residue was washed with $95 \%$ ethanol, then twice with distilled water and dried overnight at $45^{\circ} \mathrm{C}$ in a hot air oven to obtain $\mathrm{RH}$ water-unextractable AX (RH-WUAX). This was then used to determine the structural carbohydrates as described above, as well as to prepare for the RH alkali-soluble AX (RH-AX) extraction.

Microstructural analysis of $\mathrm{RH}$ after microwave pretreatment. A scanning electron microscope (SEM, EDS 6610LV, JEOL Ltd., Tokyo, Japan) was used to observe the surface morphology of the microwavepretreated $\mathrm{RH}$. The samples were dried at $65^{\circ} \mathrm{C}$ for $24 \mathrm{~h}$ in a hot air oven, then ground and passed through a 40 mesh sieve. The dried samples were mounted on aluminum, coated with gold, and then viewed at an accelerating voltage of $15 \mathrm{kV}$ with magnification of 200 to 1000 . The diameter of the final beam spot on the sample was $40 \mathrm{~nm}$.

Extraction of alkali-soluble RH-AX. RH-WUAX was suspended in $2 \%(\mathrm{w} / \mathrm{v})$ sodium hydroxide ( $1 \mathrm{~g}$ : $25 \mathrm{~mL}$ ) at $30{ }^{\circ} \mathrm{C}$ with continuous shaking at $180 \mathrm{rpm}$ for $24 \mathrm{~h}$. Subsequently, the alkali-soluble AX liquor was collected by centrifugation at $9000 \mathrm{rpm}$ and $25^{\circ} \mathrm{C}$ for $15 \mathrm{~min}$. The liquor was adjusted to $\mathrm{pH} 6.0$ with $37 \%$ hydrochloric acid, and then $95 \%$ ethanol was added to a final ethanol concentration of $80 \%(\mathrm{v} / \mathrm{v})$ to precipitate RH-AX. The precipitate was centrifuged at $9000 \mathrm{rpm}$ at $4{ }^{\circ} \mathrm{C}$ for $10 \mathrm{~min}$, washed with acetone and dried for $24 \mathrm{~h}$ at $45^{\circ} \mathrm{C}$ in a hot air oven to obtain crude RH-AX. The total sugar content was determined using the phenol-sulfuric method, using glucose as a standard ${ }^{28}$. The reducing sugar content was determined using the dinitrosalicylic acid method (DNS), using xylose as a standard ${ }^{29}$.

Enzymatic hydrolysis of XOS and AXOS production from RH-AX. Hydrolysis of RH-AX was performed using the two commercial xylanases Pentopan Mono BG and Ultraflo Max. Briefly, 2\% (w/v) RH-AX was suspended in $100 \mathrm{mM}$ sodium phosphate buffer at $\mathrm{pH}$ 5.0. Then, each xylanase was separately added at enzyme concentrations of 50, 150 and $300 \mathrm{U} / g$ substrate, and incubated at $50{ }^{\circ} \mathrm{C}$ in a water bath shaker at $170 \mathrm{rpm}$ for $24 \mathrm{~h}$. Samples were periodically taken at pre-set times and the reaction was stopped by boiling for $5 \mathrm{~min}$. The samples were then dried with a freeze dryer (FreeZone 18 Liter Console Freeze Dryer, Labconco Corp., USA) to obtain an RH oligosaccharide (RH-XOS). Total reducing sugar content was measured by the DNS method, and the carbohydrate profile was screened by thin layer chromatography (TLC). The XOS composition was qualitatively checked by TLC following the method of Jaichakan et al. ${ }^{30}$. In brief, TLC silica gel 60 (Merck, Germany) was used as the stationary phase. The mobile phase consisted of an n-butanol:acetic acid:water solution in a ratio of 2:1:1 by volume. The TLC sheet was sprayed with $10 \%$ sulfuric acid in ethanol solution containing $0.2 \%$ orcinol. The bands were developed once by heating in a hot air oven at $110^{\circ} \mathrm{C}$. The mixed XOS (X1-X6) (Wako, Japan) was used as the standard, while HPAEC was used to identify the profiles of XOS and AXOS.

Xylanase activity was determined by incubating $50 \mu \mathrm{L}$ of the diluted enzyme with $50 \mu \mathrm{L}$ of $1 \%$ birch wood xylan in $0.1 \mathrm{M}$ sodium phosphate buffer at $\mathrm{pH} 6.5,50^{\circ} \mathrm{C}$. After $10 \mathrm{~min}$, the reaction was stopped by adding $300 \mu \mathrm{l}$ of DNS reagent. Color was developed by boiling the reaction in water for $10 \mathrm{~min}$, and the process was immediately stopped by placing the reaction tube in a cold water bath. The absorbance was measured at $540 \mathrm{~nm}$ and compared to a xylose standard $(0-1.0 \mathrm{mg} / \mathrm{mL})$ after $600 \mu \mathrm{L}$ of distilled water were added and mixed well. 

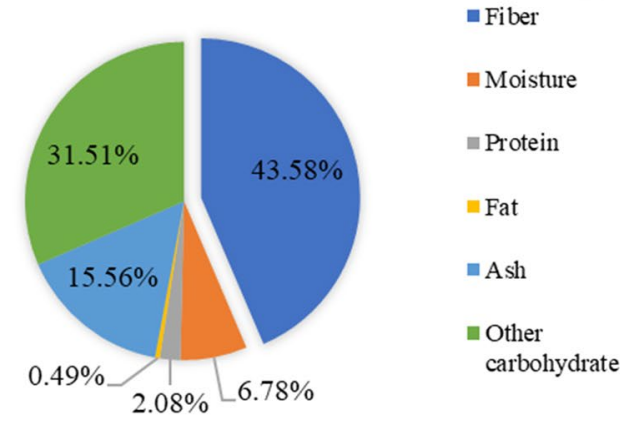

\begin{tabular}{|l|c|c|}
\hline \multirow{2}{*}{ Polymeric sugar } & \multicolumn{2}{|c|}{ Content (wt\%) } \\
\cline { 2 - 3 } & $\mathrm{RH}$ & Extractive free $\mathrm{RH}$ \\
\hline Arabinan & $1.71 \pm 0.05$ & $1.58 \pm 0.06$ \\
\hline Galactan & $0.70 \pm 0.04$ & $0.64 \pm 0.05$ \\
\hline Glucan & $29.91 \pm 0.87$ & $32.53 \pm 0.75$ \\
\hline Xylan & $10.93 \pm 0.35$ & $11.57 \pm 0.27$ \\
\hline Mannan & Not detected & Not detected \\
\hline AX content & $12.64 \pm 0.35$ & $13.15 \pm 0.29$ \\
\hline
\end{tabular}

Figure 1. Chemical composition of $\mathrm{RH}(\mathbf{A})$ and polymeric sugar content of $\mathrm{RH}$ and extractive free $\mathrm{RH}(\mathbf{B})$. Abbreviation: AX, arabinoxylan. AX content $=($ arabinose content + xylose content $)(\mathrm{wt} \%) \times 0.88$.

One unit of xylanase activity $(\mathrm{U})$ was defined as the amount of enzyme liberating one $\mu \mathrm{mol}$ of reducing sugar equivalents from $1 \%$ birch wood xylan per min at $50{ }^{\circ} \mathrm{C}$.

Lactic acid bacterial growth promotion of RH-XOS. The RH-XOS and commercial prebiotic utilization of lactic acid strains were evaluated in 96-well microplates. Lactobacillus plantarum JCM1149T, Lactobacillus sakei JCM1157, and Lactobacillus bulgalicus JCM1002 were purchased from the Japan Collection of Microorganisms. Lactobacillus brevis TISTR860 was purchased from the Thailand Institute of Scientific and Technological Research (Bangkok, Thailand). Lactobacillus johnsonii KUNN19-2, Lactobacillus reuteri KUB-AC5, and Lactococcus lactis KA-FF-1-4 were obtained from Kasetsart University, Thailand. The strain KUNN19-2 was isolated from Thai-style fermented pork, KUB-AC5 was isolated from chicken intestine and KA-FF-1-4 was isolated from fermented fish ${ }^{31-33}$. The strains were pre-cultured in De Man, Rogosa and Sharpe (MRS) broth at $37^{\circ} \mathrm{C}$ for $18 \mathrm{~h}$. MRS broth was reconstituted without glucose according to Nakphaichit et al. ${ }^{34}$ as follows: peptone $1 \%$, beef extract $1 \%$, yeast extract $0.5 \%$, dipotassium hydrogen phosphate $0.2 \%$, sodium acetate, ammonium monohydrogen citrate $0.2 \%$, magnesium sulfate $0.01 \%$, manganese sulfate $0.005 \%(\mathrm{w} / \mathrm{v})$ and Tween $800.1 \%(\mathrm{v} / \mathrm{v})$. The initial $\mathrm{pH}$ of the medium was adjusted to 6.5 by $1 \mathrm{M}$ sodium hydroxide or $1 \mathrm{M}$ hydrochloric acid and autoclaved at $121^{\circ} \mathrm{C}$ for $15 \mathrm{~min}$. Xylose, XOS95P, RMD, inulin and glucose were dissolved in modified MRS, and filtered through a sterile $0.2 \mu \mathrm{m}$ filter $0.2 \mu \mathrm{m}$ and added to the media to a final concentration of $2 \%(\mathrm{w} / \mathrm{v})$, whereas $\mathrm{RH}-\mathrm{XOS}$ was used with $2 \%$ reducing sugar content. The microplates were inoculated with cultured lactic acid bacteria at a final concentration of $1 \times 10^{4} \mathrm{CFU} / \mathrm{mL}$, and sterile sealing tape was used to prevent vaporization and contamination. The samples were incubated at $37^{\circ} \mathrm{C}$ for $24 \mathrm{~h}$. Growth parameters were monitored using a microplate reader (UV-Vis SpectraMax 190 Microplate Reader, Molecular Devices, Sunnyvale, CA, USA) at $600 \mathrm{~nm}$.

Continuous in vitro digestion of RH-XOS. The method of in vitro digestion followed Minekus et al. ${ }^{35}$. Briefly, RH-XOS, XOS95P, RMD and inulin were added into the simulated salivary fluid (SSF), simulated gastric fluid (SGF) and simulated intestinal fluid (SIF) to study the sugar release. The samples were first added with SSF, and two percentages of sample solutions were mixed with SSF electrolyte stock solution at a ratio of 50:50 (v/v). Amylase solution was added to achieve $75 \mathrm{U} / \mathrm{mL}$ in the final mixture at $\mathrm{pH} 7.0$ and incubated for $5 \mathrm{~min}$. The oral bolus sample was mixed with SGF electrolyte stock solution at a final ratio of 50:50 (v/v). Porcine pepsin was added to achieve $2000 \mathrm{U} / \mathrm{mL}$ in the final mixture at pH 3.0 and incubated for $2 \mathrm{~h}$. Lastly, gastric chyme was mixed with SIF electrolyte stock solution at a final ratio of 50:50 (v/v). Pancreatin solution was added to achieve $200 \mathrm{U} / \mathrm{mL}$ in the final mixture at $\mathrm{pH} 7.0$ and incubated for $2 \mathrm{~h}$. Bile salts were added to give a final concentration of $10 \mathrm{mM}$ in the final mixture.

Total sugar and reducing sugar contents of samples in each phase were determined using the phenol-sulfuric acid and DNS methods, respectively. The percentage of hydrolysis was calculated as described by Korakli et al. ${ }^{36}$ :

$$
\text { Digestion }(\%)=\frac{(\text { final reducing sugar content }- \text { initial reducing sugar content }) \mathrm{ppm}}{(\text { total sugar content }- \text { initial reducing sugar content }) \mathrm{ppm}} \times 100
$$

Statistical analysis. Three independent trials were conducted for each treatment, with mean values and standard deviations of the data calculated. Statistical analyses were carried out using SPSS 11 software. Duncan's one-way multiple comparisons were performed to determine significant differences $(P<0.05)$.

\section{Results}

Chemical and carbohydrate composition of RH. RH contained mainly fiber at $43.58 \%$, followed by other carbohydrate, ash, moisture protein and fat at 31.51, 15.56, 6.782 .05 and 0.49\%, respectively (Fig. 1A). RH has lignocellulosic fibers, which are formed by cellulose, hemicellulose and lignin. RH is also highly siliceous and different from other biomass materials. According to previous reviews, $\mathrm{RH}$ ranged from 15 to $20 \%$ of ash content. However, values depended on the state of prevention of RH degradation after harvesting ${ }^{37}$. RH is composed of three primary components as cellulose, hemicelluloses and lignin. Di Blasi et al. ${ }^{38}$ demonstrated that rice husk was a good source of lignocellulosic materials, comprising $28.6 \%$ hemicellulose, $28.6 \%$ cellulose, $24.4 \%$ lignin 


\begin{tabular}{|c|c|c|c|c|c|}
\hline \multirow[b]{2}{*}{ Temperature $\left({ }^{\circ} \mathrm{C}\right)$} & \multirow[b]{2}{*}{ Time (min) } & \multicolumn{3}{|c|}{ Content (wt\%) } & \multirow[b]{2}{*}{ A/X ratio } \\
\hline & & A1 & $\mathrm{X1}$ & AX content & \\
\hline \multirow{3}{*}{140} & 5 & $2.08 \pm 0.12$ & $8.61 \pm 0.54$ & $9.01 \pm 0.30^{\mathrm{a}}$ & 0.24 \\
\hline & 10 & $1.88 \pm 0.08$ & $7.79 \pm 0.25$ & $8.51 \pm 0.24^{\mathrm{bc}}$ & 0.24 \\
\hline & 15 & $1.81 \pm 0.24$ & $8.15 \pm 0.20$ & $8.76 \pm 0.18^{\mathrm{b}}$ & 0.22 \\
\hline \multirow{3}{*}{160} & 5 & $1.80 \pm 0.16$ & $6.88 \pm 0.30$ & $8.31 \pm 0.23^{\mathrm{cd}}$ & 0.26 \\
\hline & 10 & $1.84 \pm 0.09$ & $7.60 \pm 0.11$ & $7.64 \pm 0.07^{\mathrm{e}}$ & 0.24 \\
\hline & 15 & $1.75 \pm 0.14$ & $7.29 \pm 0.04$ & $7.96 \pm 0.05^{\mathrm{cd}}$ & 0.24 \\
\hline \multirow{3}{*}{180} & 5 & $1.68 \pm 0.20$ & $7.70 \pm 0.18$ & $8.25 \pm 0.21^{\mathrm{cd}}$ & 0.22 \\
\hline & 10 & $1.68 \pm 0.04$ & $6.89 \pm 0.15$ & $7.54 \pm 0.10^{\mathrm{e}}$ & 0.24 \\
\hline & 15 & $1.69 \pm 0.15$ & $8.47 \pm 0.08$ & $8.94 \pm 0.15^{\mathrm{a}}$ & 0.20 \\
\hline
\end{tabular}

Table 1. Water-unextractable arabinoxylan content after microwave processing. Values with different superscript letters in the same column are significantly different $(P<0.05)$. Abbreviations: $\mathrm{A} 1$, arabinose; X1, xylose; AX; arabinoxylan. AX content $=($ arabinose content + xylose content $)($ wt $\%) \times 0.88$.

and $18.4 \%$ extractive matter. The cellulose and hemicellulose components are both polysaccharides that can be converted to functional sugars. The main hemicellulose compound in RH is xylan. This is made up of substituted arabinoxylan that can be used as a precursor for XOS and AXOS production ${ }^{39,40}$.

Lignocellulosic fiber of RH was divided into polymeric sugar, consisting of $1.71 \%$ arabinan, $0.70 \%$ galactan, $29.91 \%$ glucan and $10.93 \%$ xylan. However, extractive-free RH after pretreatment with acetone and ethanol consisted of $1.58 \%$ arabinan, $0.64 \%$ galactan, $32.53 \%$ glucan and $11.57 \%$ xylan (Fig. 1B). Glucose is a sugar with six carbon atoms that is found in most plant structures. However, glucose can be absorbed in the upper gastrointestinal tract and enhances the growth of pathogens in human microbiota, exhibiting no prebiotic properties. Interestingly, $\mathrm{RH}$ also contains a high amount of xylose as 5 carbon atom sugar that enhances the growth of probiotics, while most pathogens cannot use it as a carbon source ${ }^{41}$. Therefore, oligosaccharides consisting of xylose oligomers in $\mathrm{RH}$ are interesting functional ingredients as prebiotic compounds. Hemicellulose is a complex component of the plant cell wall, which is associated with cellulose and lignin in a hetero-matrix form. Hemicellulose forms ether and ester bonds with lignin, while hydrogen bonds form with cellulose ${ }^{42}$. Pretreatment of lignocellulosic materials increases biological conversion yields by disrupting interpolymer linkages and allowing the lignocellulose fractions to separate.

Effects of microwave treatment on AX extraction. Hemicellulose extraction with an alkaline reagent and subsequent hydrolysis in the presence of acid or enzyme is preferred, due to its high XOS output yield from sugarcane bagass $\mathrm{e}^{43}$. Furthermore, AX alkaline extraction can be assisted by microwaves because the energy is uniformly distributed throughout the material as opposed to conventional heating. Process time can thus be reduced, resulting in greater efficiency and homogeneity ${ }^{20,44}$. Microwave treatment causes fragmentation and swelling, leading to lignin and hemicellulose degradation in the biomass and improving the pentose yield ${ }^{45}$. Table 1 shows that AX content slightly decreased after microwave pretreatment at $140-180^{\circ} \mathrm{C}$ for $5-15$ min with increasing temperature and processing time. The highest $\mathrm{AX}$ content of $9.01 \mathrm{~g} / 100$ was recorded after $5 \mathrm{~min}$ at $140{ }^{\circ} \mathrm{C}$ showing no significant difference with $15 \mathrm{~min}$ at $180^{\circ} \mathrm{C}$. However, A/X ratio of the $\mathrm{AX}$ of $180^{\circ} \mathrm{C}$ for 15 min was lower indicating less branches of arabinoxylan that can ease the xylanase enzyme to access the arabinoxylan backbone in hydrolysis process ${ }^{46}$.

Figure 2A, B show that reducing sugar and total sugar content increased significantly with increasing temperature during microwave treatment. Microwave treatment at $180{ }^{\circ} \mathrm{C}$ for $15 \mathrm{~min}$ gave the highest reducing sugar and total sugar contents of 20.75 and $88.3 \mathrm{mg} / \mathrm{g}$, respectively. The preliminary experiment, alkali extraction of $\mathrm{RH}$ without microwave treatment, provided reducing sugar and total sugar contents of 0.9 and $48.4 \mathrm{mg} / \mathrm{g}$ (data not shown). Operating parameters that affected microwave conversion efficiency of sugar-biomass assisted pretreatment were discussed by Ethaib et al. ${ }^{47}$. They reported that biomass load, power level of the microwave and time of irradiation all affected the efficiency of microwave pretreatment to convert biomass into sugar. Microwave-assisted pretreatment of lignocellulosic biomass immersed in alkaline glycerol showed increased enzyme hydrolysis of corn straw and rice husk to sugar production ${ }^{48}$. The AX concentration in spent grains from the brewing process was maximized under pretreatment conditions of microwave heating at $172{ }^{\circ} \mathrm{C}$ and $0.38 \mathrm{M}$ sodium hydroxide ${ }^{49}$. Microwave processing at $140^{\circ} \mathrm{C}$ for 5 min provided the highest $\mathrm{AX}$ content but the $\mathrm{A} / \mathrm{X}$ ratio was high, as shown in Table 1 . Lafond et al. ${ }^{46}$ reported that enzymes were less sensitive to an increase in the $\mathrm{A} / \mathrm{X}$ ratio at high $\mathrm{A} / \mathrm{X}$ ratio. The effect of $\mathrm{A} / \mathrm{X}$ ratio on enzymatic hydrolysis was determined and results revealed that extracted $\mathrm{AX}$ with a lower $\mathrm{A} / \mathrm{X}$ ratio had higher reducing sugar content (data not shown). Therefore, the optimal condition for hemicellulose extraction was $180^{\circ} \mathrm{C}$ for $15 \mathrm{~min}$, providing $3.5 \%$ AX yield of RH, as shown in Fig. 2C. For XOS and AXOS production, extracted RH-AX was further hydrolysed by commercial xylanase.

The preliminary study compared the activity of endoxylanases in hydrolysis of untreated and microwavetreated $\mathrm{RH}$. Results showed that in microwave-treated $\mathrm{RH}$, the reducing sugar content was more than 2 folds higher compared with the untreated sample (data not shown). SEM was used to investigate the surface morphology of RH before and after microwave pretreatment. SEM images of untreated and treated RH showed remarkable changes in the surface structure. As shown in Fig. 3A, the untreated RH surface had a packed structure with the 


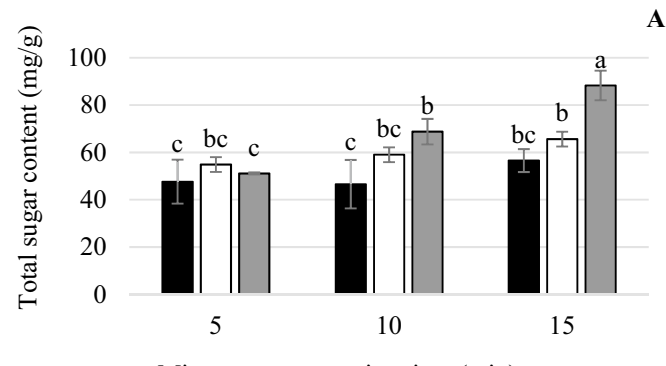

B
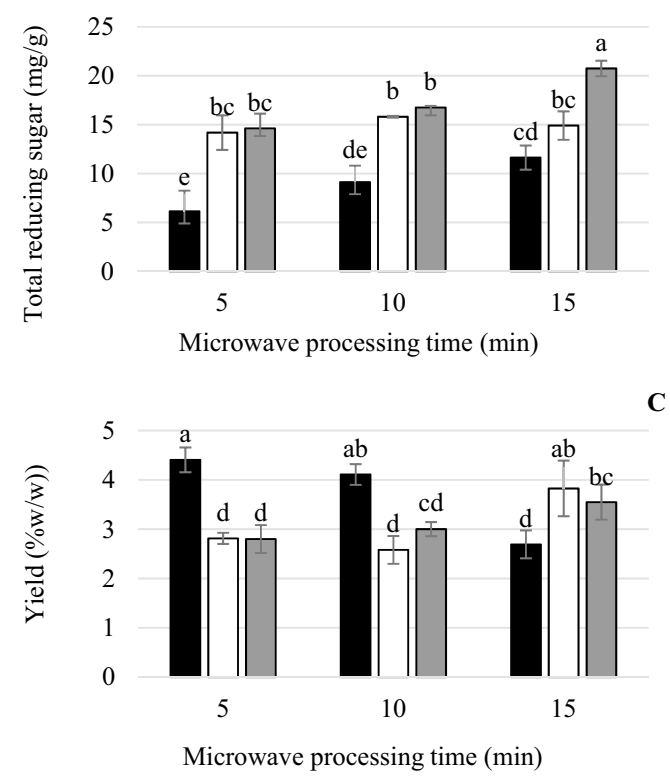

Figure 2. Total reducing sugar content $(\mathbf{A})$, total sugar content $(\mathbf{B})$ and yield $(\mathbf{C})$ by $\mathrm{RH}(1.5 \mathrm{~g}$ in $45 \mathrm{~mL}$ of water) after microwave processing at $140{ }^{\circ} \mathrm{C}$ (black square), $160{ }^{\circ} \mathrm{C}$ (white square) and $180{ }^{\circ} \mathrm{C}$ (grey square) for 5-15 min. For each temperature and time of microwave treatment, different superscript letters indicate significant difference $(P<0.05)$.
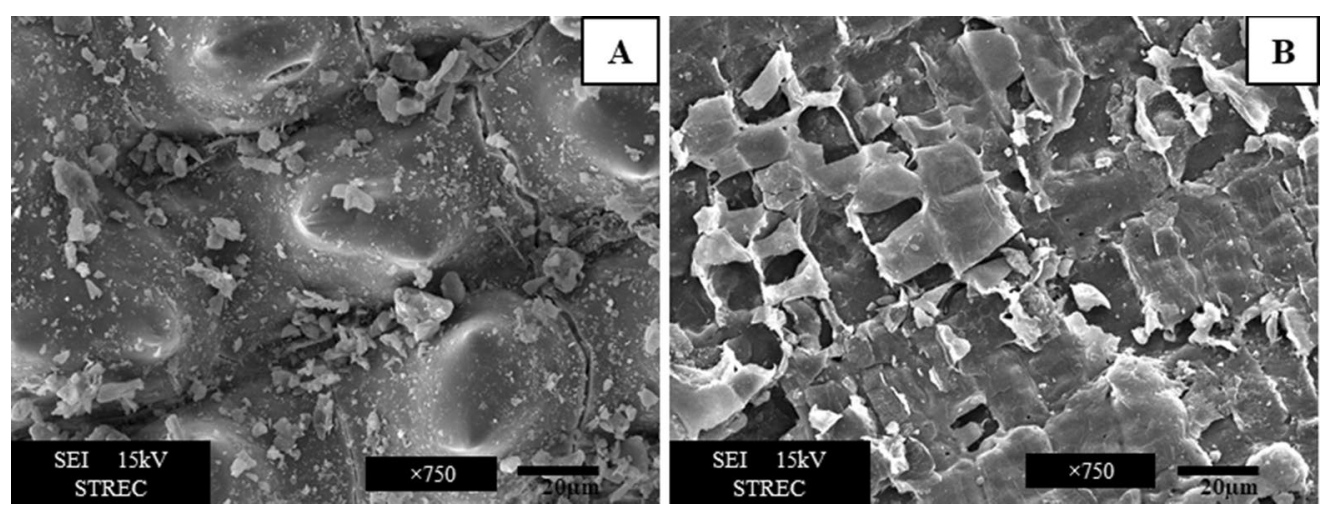

Figure 3. Scanning electron microscopy (SEM) analysis of untreated RH (A) and the pretreated RH (B) with microwave at $180^{\circ} \mathrm{C}$ for $15 \mathrm{~min}$.

composition of the plant cell wall and some convex structures. According to the baseline data of raw $\mathrm{RH}$, the outer surface of the raw RH consisted mainly of carbon, oxygen, nitrogen and silica. The complex lignocellulosic structure of RH has very low lignocellulosic-degrading enzyme permeability. Microwave pretreatment was expected to degrade the cell wall sufficiently and increase the surface area of the $\mathrm{RH}$ structure to allow direct contact with the degrading enzyme. Figure 3B shows that the surface morphology of the treated RH varied remarkably. Thermal treatment induced fragmentation and swelling, leading to lignin and hemicellulose degradation in the biomass ${ }^{50}$. 


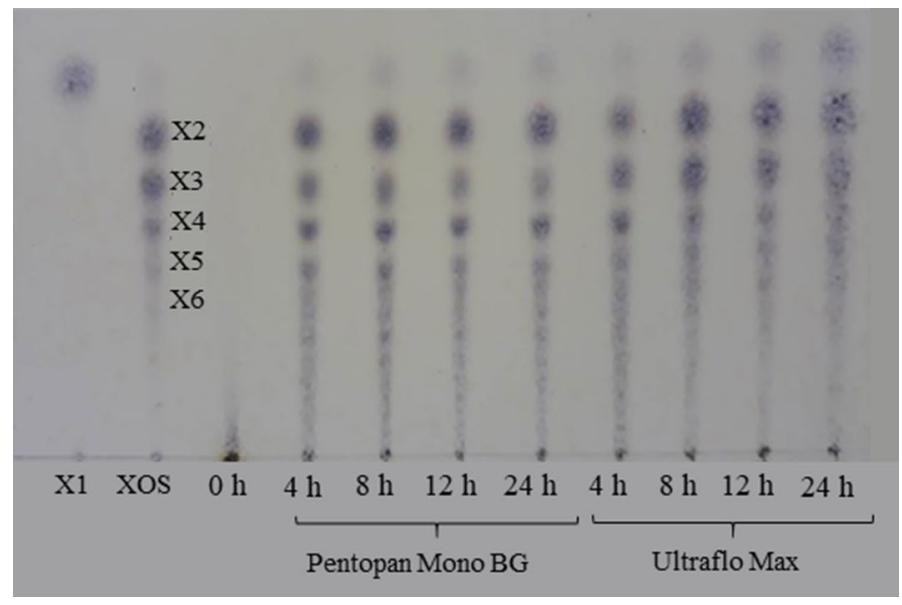

Figure 4. TLC chromatograms of XOS obtained from RH-AX after hydrolysis with different commercial xylanases at $50 \mathrm{U} / \mathrm{g}, 50^{\circ} \mathrm{C}, \mathrm{pH} 6.0$ for $0-24 \mathrm{~h}$. Mixtures X1-X6 were used as standards.

Alkaline pretreatment enhanced enzymatic hydrolysis by selectively removing lignin without damaging the carbohydrates and increasing porosity and surface area ${ }^{51}$. Binod et al. ${ }^{52}$ reported that the crystallinity index of native sugarcane bagasse was lower than other pretreated samples, according to the X-ray diffraction profiles of native and microwave-pretreated samples. Crystalline size of native sugarcane bagasse was greater than the pretreated sugarcane bagasse due to degradation of the linkages between lignin and hemicellulose and subsequent removal of lignin, which increased the surface area. Furthermore, non-thermal effects of exposure degraded the lignocellulose structure, while other physical parameters caused fluctuation and vibration of the charged particles and tissues ${ }^{53}$. Wang and $\mathrm{Lu}^{54}$ reported that the effect of microwave treatment on XOS production from wheat bran with xylanase was characterized by rapid increase in the reducing sugar by almost 3-4 folds, compared with untreated wheat bran. Microwave alkaline extraction of AX produced various lignocellulosic residues. Roos et al. ${ }^{55}$ reported that microwave treatment considerably enhanced the xylose ratio of barley husks, while Jiang et al. ${ }^{56}$ reported that ultrasonic-microwaves synergetically increased arabinoxylan content in corn bran more than the conventional method.

Effects of commercial xylanases on XOS and AXOS production. Oligosaccharide profiles were observed by TLC during 0-24 h of incubation, compared to mixtures of X1-X6 as standards (Fig. 4). The TLC did not exhibit a sugar band before RH-AX was incubated with xylanases, indicating that it could be a long-chain carbohydrate. Incubations using Pentopan Mono BG and Ultraflo Max hydrolysed long-chain carbohydrate into short-chain oligosaccharides. The TLC results confirmed that both enzymes gave similar sugar patterns, including X1, X2, X3 X4 and X5. However, Ultraflo Max hydrolysed the substrate to a degree of polymerisation (DP) and produced predominantly more monosaccharides than Pentopan Mono BG. XOS produced by Pentopan Mono BG provided various kinds of oligosaccharides from X2 to X5.

Furthermore, the oligosaccharide hydrolysates of RH-AX produced by both commercial xylanases were analyzed by HPAEC for sugar patterns. Results demonstrated that Pentopan Mono BG produced oligosaccharide hydrolysate with the highest total oligosaccharide content at $150 \mathrm{U} / \mathrm{g}$ of enzyme concentration, after 12 and $24 \mathrm{~h}$ of incubation (Fig. 5A), while the Ultraflo Max produced oligosaccharide hydrolysate with the highest total oligosaccharide content at $50 \mathrm{U} / \mathrm{g}$ of enzyme concentration after $8 \mathrm{~h}$ of incubation (Fig. 5B). The presence of exo-xylanases in the commercial enzyme gave increased concentration and incubation time with increased total monosaccharide content. Increased concentration allowed undesirable enzyme activity to hydrolyse the short-chain oligomer into monosaccharide, resulting in a significant decrease in XOS production. Furthermore, the longer an enzyme was incubated with its substrate, the greater the hydrolysis activity and amount of smallest products formed.

The HPAEC chromatograms showed that both commercial enzymes provided X2 and X3 as the main oligosaccharide found in the hydrolysates of RH-AX, followed by X4, X5 and X6 as minor oligosaccharide. Interestingly, AXOS was found in both hydrolysates (Fig. 6A, B). Quantitative analyses of XOS and AXOS produced by both commercial xylanases are shown in Supplementary Tables S1 and S2. The oligosaccharide produced by Pentopan Mono BG exhibited A2XX, A3X, XA3XX and A2,3XX as 55.96, 784.68, 171.20 and $687.55 \mathrm{mg} / \mathrm{L}$, respectively while the oligosaccharide produced by Ultraflo Max exhibited A2XX and XA3XX as 670.72 and 590.46 mg/L, respectively. In this study, oligosaccharide produced by Pentopan Mono BG was then used to evaluate the prebiotic properties because it contained less monosaccharide and various kinds of oligosaccharides.

In the carbohydrate-active enzyme (CAZY) database, xylanases are classified based on primary structure comparisons of the catalytic domains and grouped in families of related sequences. Members of the same family have similar protein folds, the same catalytic mechanism and anomeric carbon retention or inversion. Enzymes from glycoside hydrolase families 5, 7 and 8 contain a catalytic domain with endo-1,4 xylanase activity but research has primarily focused on xylanases from glycoside hydrolase families 10 and $11^{57}$. Pentopan Mono BG and Ultraflo Max belong to the glycoside hydrolase families 10 and 11, showing some differences in sugar profiles ${ }^{58}$. Family 


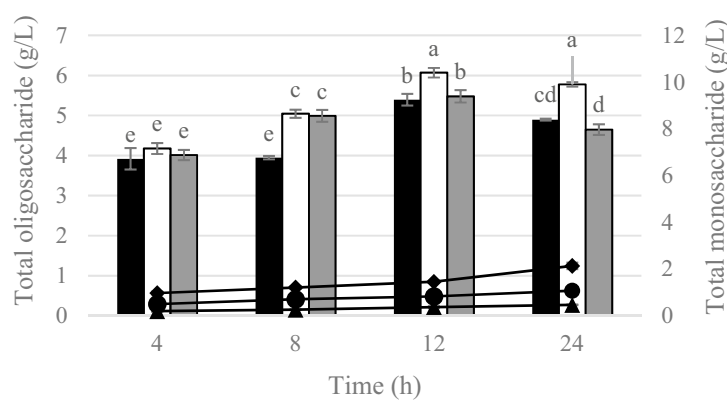

B

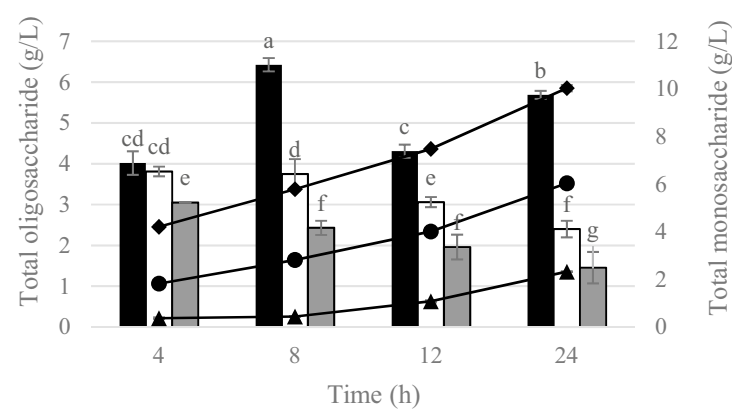

Figure 5. Bars showing total oligosaccharide contents when treating RH-AX with Pentopan Mono BG (A) and Ultraflo $\operatorname{Max}$ (B) at 50 (black square), 150 (white square) and 300 (grey square) U/g substrate of enzyme concentration. Solid lines with markers show total monosaccharide content hydrolysate when treating RH-AX with the commercial xylanases at 50 (black filled triangle), 150 (black filled circle) and 300 (black filled diamond) $\mathrm{U} / \mathrm{g}$ substrate of enzyme concentration at $50^{\circ} \mathrm{C}, \mathrm{pH} 6.0$ for $0-24 \mathrm{~h}$. Different superscripts for each enzyme concentration and time of enzyme hydrolysis represent significant differences $(P \leq 0.05)$.
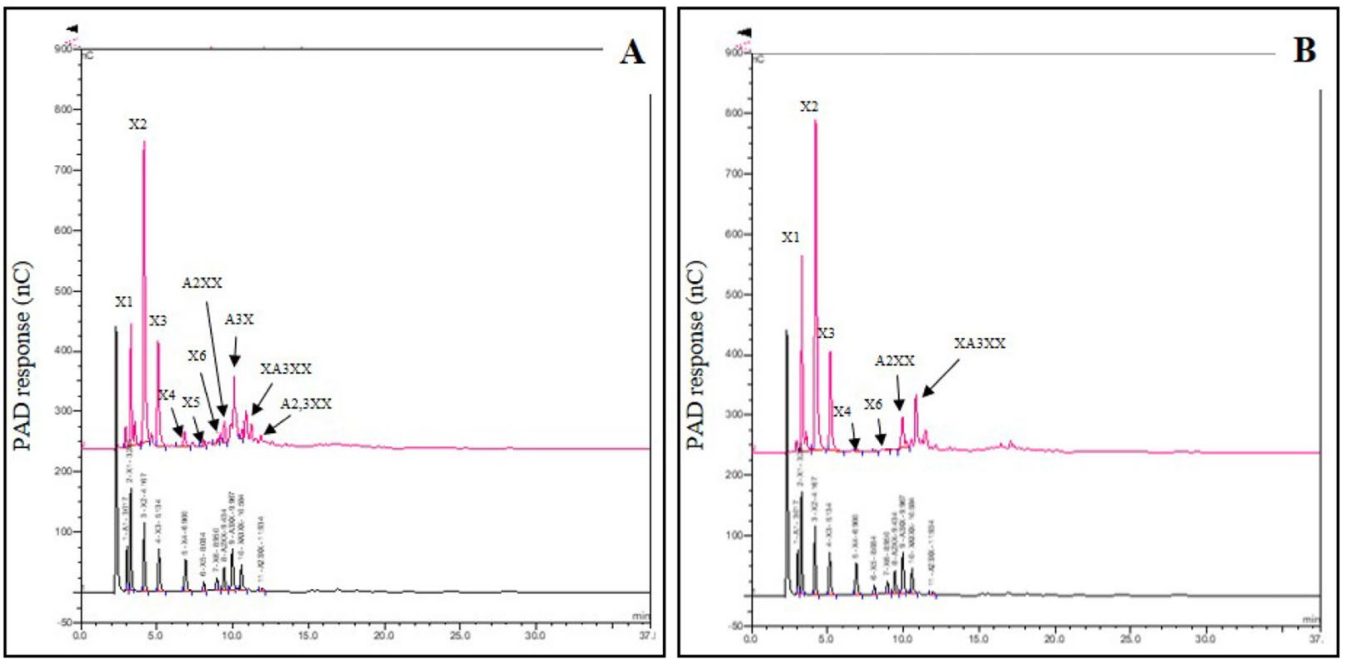

Figure 6. HPAEC chromatograms of oligosaccharides from RH-AX treated with Pentopan Mono BG at $150 \mathrm{U}$, $50{ }^{\circ} \mathrm{C}$ for $12 \mathrm{~h} \mathrm{(A)}$ and Ultraflo Max at $50 \mathrm{U}, 50^{\circ} \mathrm{C}$ for $8 \mathrm{~h}(\mathbf{B})$.

11 xylanases hydrolyse only xylan and generally exhibit a preference for internal xylan bonds and unsubstituted xylan chains. They act primarily on the xylose unit at the center of the oligosaccharide. Conversely, family 10 xylanases tend to show preference for groups at the end of the xylan bonds, especially favoring the reducing end. They have low substratum specificity and can degrade xylan backbones with several replacements by hydrolysing at the side branch location ${ }^{59}$. Pentopan mono BG produced XOS from Phoenix dactylifera L. seed with higher amounts of X3 than $\mathrm{X} 2^{60}$. Falk et al. ${ }^{61}$ reported that GH10 xylanases produced a higher amount of short-chain 


\begin{tabular}{|c|c|c|c|c|c|}
\hline \multirow[b]{2}{*}{ Microorganism } & \multicolumn{5}{|c|}{ Carbohydrate sources } \\
\hline & Xylose & XOS95P & RMD & Inulin & RH-XOS \\
\hline Lactobacillus johnsonii & - & + & + & + & + \\
\hline Lactobacillus plantarum & - & + & + & + & + \\
\hline Lactobacillus reuteri & - & + & + & + & + \\
\hline Lactobacillus bulgaricus & - & + & + & + & + \\
\hline Lactobacillus sakei & - & + & + & + & + \\
\hline Lactococcus lactic & - & + & + & + & - \\
\hline Lactobacillus brevis & + & + & + & - & + \\
\hline
\end{tabular}

Table 2. Carbohydrate utilization by lactic acid bacteria. + : Carbohydrates can promote growth of lactic acid bacteria. - : Carbohydrate cannot promote growth of lactic acid bacteria. XOS95P 95\% commercial XOS, RMD resistant maltodextrin, $\mathrm{RH}$-XOS xylo-oligosaccharide obtained from rice husk.

XOS from rye bran than GH11. According to the datasheet of the enzymes, GH10 prefers to hydrolyse xylan into short-chain XOS, while GH11 prefers to hydrolyse into long-chain XOS.

Growth promotion of lactic acid bacteria by $\mathrm{RH}-\mathrm{XOS}$. A prebiotic is a selectively fermented ingredient that allows for specific changes in the composition and/or activity of the gastrointestinal microbiota, which confers benefits. It is necessary to establish clear criteria for classifying a food ingredient as a prebiotic ${ }^{62}$. XOS and AXOS possess promising functional properties as they can be specifically fermented by intestinal commensals such as bifidobacteria and lactobacilli ${ }^{3}$. XOS has high prebiotic potential and can be incorporated into a wide range of food products. Seven strains of lactic acid bacteria were used to evaluate the ability of RH-XOS to promote growth compared to xylose and commercial prebiotics, including XOS95P, RMD and inulin. Table 2 shows the utilization of RH-XOS and commercial prebiotics by lactic acid bacteria strains. XOS95P and RMD promoted the growth of all the strains, whereas RH-XOS did not promote L. Lactis. Only L. brevis grew well on xylose. A previous study also found that L. brevis grew better on xylose than on a glucose and xylose mixture ${ }^{64}$. Inulin and $\mathrm{RH}-\mathrm{XOS}$ promoted six strains except L. brevis. Kariyawasam et al. ${ }^{65}$ revealed that inulin partially promoted L. brevis strains, while L. brevis displayed high growth and consumption in $\mathrm{XOS}^{66}$. The results of this study also demonstrated that the ability of probiotic bacteria to utilize prebiotics varies, even within the same species. Iliev et al. ${ }^{67}$ reported that XOS with different DPs stimulated the growth of some heterofermentative Lactobacillus strains. Approximately 30 strains were identified and screened for XOS utilization. Results showed that the three enzymes $\beta$-xylosidase, exo-oligoxylanase and $\alpha$-L-arabinofuranosidase could alter the end-products and morphology of Lactobacillus strain growth by XOS.

In vitro simulation of human digestibility of RH-XOS. Human-simulated digestion typically includes the oral, gastric and small intestinal phases. These phases were performed to study the digestion resistance property of RH-XOS compared with commercial prebiotics. Figure 6 shows that the carbohydrate used in this study was significantly hydrolysed in the gastric phase and small intestinal phase. Commercial XOS and RMD were not digested in the oral phase because commercial XOS mostly contain short-chain oligomers, which are less than DP 4. Alpha-amylase is a glycoside hydrolase family 13, which catalyses the hydrolysis of (1-4)- $\alpha$-dglucosidic linkages in polysaccharides. Substrates are not digested by $\alpha$-amylase, such as $\alpha$-limit dextrin, and small linear oligomers, along with larger $\alpha$-glucans ${ }^{68}$. By contrast, inulin and RH-XOS were digested in small amounts in the oral phase at $1.01 \%$ and $7.08 \%$, respectively. In a previous study, commercial XOS (DP 2-4) and inulin did not degrade when incubated with salivary amylase enzyme but they may have an impact on digestion, which is defined as the hydrolytic and other processes that occur in the stomach and small intestine ${ }^{69,70}$. This result could be due to an impure composition hydrolysed by salivary a-amylase, which catalyzed the hydrolysis of $\alpha$-glycosidic bonds of polysaccharide starch ${ }^{71}$. In the gastric phase, the percentage of digestion increased in all samples, especially inulin and RH-XOS at $19.05 \%$ and $21.30 \%$, respectively as the stomach plays an enhanced role in hydrolysis by hydrochloric acid ${ }^{68}$. Commercial XOS was digested in the gastric phase and small intestinal phase at the same digestion level of $12.21 \%$ and $11.23 \%$, respectively. Inulin and RH-XOS were less digested in the intestinal phase, while RMD was more digested in the intestinal phase, (23.24\%) (Fig. 7). Exo-glucosidases that act on the non-reducing end of glucose oligomers and catalyse not only the hydrolysis of $\alpha$-1,4-glycosidic bonds, but also to a lesser extent $a-1,6$ glycosidic bonds, ensuring further degradation of nonlinear oligosaccharides ${ }^{68}$. This study found that the obtained RH-XOS was more than 70\% resistant to human simulated digestion, similar to commercial prebiotics. According to previous research, XOS are resistant to hydrolysis by enzymes and/or the low $\mathrm{pH}$ found in human saliva, gastric, and pancreatic juices. XOS are not absorbed during transit through the small intestine ${ }^{68}$. Eventually the XOS are able to reach the colon and serve as fermentable substrates for certain members of the resident.

\section{Conclusion}

Results showed that microwave pretreatment is a promising method for lignocellulosic-degradation of RH. Commercial xylanases, Pentopan Mono BG, and Ultraflo Max were able to hydrolyse RH-AX into XOS and AXOS. Pentopan Mono BG provided fewer monosaccharides and various kinds of oligosaccharides compared to 


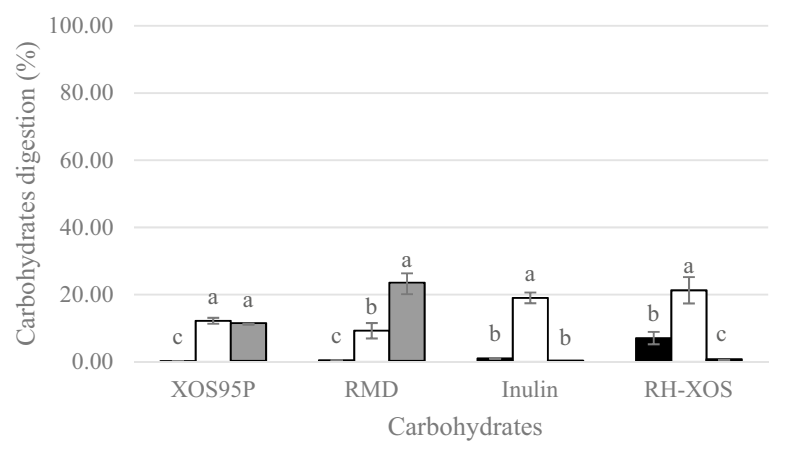

Figure 7. Percentage of digested carbohydrate in in vitro simulated digestion in oral phase (black square), gastric phase (white square) and intestinal phase (grey square). For each simulated digestion phase, different superscript letters show significant difference $(P<0.05)$.

Ultraflo Max. RH-XOS prepared by Pentopan Mono BG promoted growth of six of the seven lactic acid bacterial species, and was resistant to human simulated digestion by more than $70 \%$, indicating high prebiotic potential.

Received: 6 July 2021; Accepted: 5 October 2021

Published online: 07 January 2022

\section{References}

1. Worasuwannarak, N., Sonobe, T. \& Tanthapanichakoon, W. Pyrolysis behaviors of rice straw, rice husk, and corncob by TG-MS technique. J. Anal. Appl. Pyrolysis 78, 265-271 (2007).

2. Hu, B. et al. On the mechanism of xylan pyrolysis by combined experimental and computational approaches. Proc. Combust. Inst. 38, 4215-4223 (2021).

3. Dornez, E., Gebruers, K., Delcour, J. A. \& Courtin, C. M. Grain-associated xylanases: Occurrence, variability, and implications for cereal processing. Trends Food Sci. Technol. 20, 495-510 (2009).

4. Abouloifa, H. et al. The prebiotics (Fructo-oligosaccharides and Xylo-oligosaccharides) modulate the probiotic properties of Lactiplantibacillus and Levilactobacillus strains isolated from traditional fermented olive. World J. Microbiol. Biotechnol. 36, 1-12 (2020)

5. Singh, R. D., Banerjee, J. \& Arora, A. Prebiotic potential of oligosaccharides: A focus on xylan derived oligosaccharides. Bioact. Carbohydr. Diet. Fiber 5, 19-30 (2015).

6. Terrasan, C. R., de Morais Junior, W. G. \& Contesini, F. J. Enzyme Immobilization for Oligosaccharide Production (Elsevier, 2019).

7. Ávila, P. F., Martins, M., de Almeida Costa, F. A. \& Goldbeck, R. Xylooligosaccharides production by commercial enzyme mixture from agricultural wastes and their prebiotic and antioxidant potential. Bioact. Carbohydr. Diet Fiber. 24, 100234 (2020).

8. Stahl, B., Zens, Y. \& Boehm, G. Prebiotics with special emphasis on fructo-, galacto-, galacturono-, and xylooligosaccharides (2007).

9. Mathew, S., Aronsson, A., Karlsson, E. N. \& Adlercreutz, P. Xylo-and arabinoxylooligosaccharides from wheat bran by endoxylanases, utilisation by probiotic bacteria, and structural studies of the enzymes. Appl. Microbiol. Biotechnol. 102, 3105-3120 (2018).

10. Juturu, V. \& Wu, J. C. Microbial exo-xylanases: A mini review. Int. J. Appl. Biotechnol. Biochem. 174, 81-92 (2014).

11. Akpinar, O., Erdogan, K. \& Bostanci, S. Enzymatic production of xylooligosaccharide from selected agricultural wastes. Food Bioprod. Process. 87, 145-151 (2009).

12. Biely, P., Vršanská, M., Tenkanen, M. \& Kluepfel, D. Endo- $\beta-1,4$-xylanase families: Differences in catalytic properties. J. Biotechnol. 57, 151-166 (1997).

13. Dodd, D. \& Cann, I. K. Enzymatic deconstruction of xylan for biofuel production. GCB Bioenergy 1, 2-17 (2009).

14. Lam, N. D., Nagasawa, N. \& Kume, T. Effect of radiation and fungal treatment on lignocelluloses and their biological activity. Radiat. Phys. Chem. Oxf. Engl. 1993(59), 393-398 (2000).

15. Aguilar-Reynosa, A. et al. Comparison of microwave and conduction-convection heating autohydrolysis pretreatment for bioethanol production. Bioresour. Technol. 243, 273-283 (2017).

16. Hoang, A. T. et al. Insight into the recent advances of microwave pretreatment technologies for the conversion of lignocellulosic biomass into sustainable biofuel. Chemosphere 281, 130878 (2021).

17. Gabhane, J., William, S. P., Vaidya, A. N., Mahapatra, K. \& Chakrabarti, T. Influence of heating source on the efficacy of lignocellulosic pretreatment-a cellulosic ethanol perspective. Biomass Bioenergy 35, 96-102 (2011).

18. Gissibl, A. et al. Microwave pretreatment of paramylon enhances the enzymatic production of soluble $\beta$-1, 3-glucans with immunostimulatory activity. Carbohydr. Polym. 196, 339-347 (2018).

19. Palm, M. \& Zacchi, G. Extraction of hemicellulosic oligosaccharides from spruce using microwave oven or steam treatment. Biomacromol 4, 617-623 (2003).

20. Coelho, E., Rocha, M. A. M., Saraiva, J. A. \& Coimbra, M. A. Microwave superheated water and dilute alkali extraction of brewers' spent grain arabinoxylans and arabinoxylo-oligosaccharides. Carbohydr. Polym. 99, 415-422 (2014).

21. Kundu, P., Kumar, S., Ahluwalia, V., Kansal, S. K. \& Elumalai, S. Extraction of arabinoxylan from corncob through modified alkaline method to improve xylooligosaccharides synthesis. Bioresour. Technol. Rep. 3, 51-58 (2018).

22. Gibson, G. R. et al. Expert consensus document: The International Scientific Association for Probiotics and Prebiotics (ISAPP) consensus statement on the definition and scope of prebiotics. Nat. Rev. Gastroenterol. Hepatol. 14, 491-502 (2017).

23. Swennen, K., Courtin, C. M. \& Delcour, J. A. Non-digestible oligosaccharides with prebiotic properties. Crit. Rev. Food. Sci. Nutr. 46, 459-471 (2006).

24. AOAC, B. A. M. Association of official analytical chemists. Official methods of analysis, Vol. 12 (2000).

25. Jaichakan, P., Thi, H. N. D., Nakphaichit, M. \& Klangphetch, W. The Effect of alkali pretreatment and acid debranching on rice husk, rice straw and defatted rice bran for xylobiose production by commercial xylanases. J. Sci. Technol. 11, 91-103 (2019). 
26. McCleary, B. V. et al. Hydrolysis of wheat flour arabinoxylan, acid-debranched wheat flour arabinoxylan and arabino-xylo-oligosaccharides by $\beta$-xylanase, $\alpha$-L-arabinofuranosidase and $\beta$-xylosidase. Carbohydr. Res. 407, 79-96 (2015).

27. Sluiter, A. et al. Determination of structural carbohydrates and lignin in biomass. Lab. Anal. Proc. 1617, 1-16 (2008),

28. Dubois, M., Gilles, K. A., Hamilton, J. K., Rebers, P. T. \& Smith, F. Colorimetric method for determination of sugars and related substances. Anal. Chem. 28, 350-356 (1956).

29. Miller, G. L. Use of dinitrosalicylic acid reagent for determination of reducing Miller sugar. Anal. Chem. 31, 426-428 (1959).

30. Jaichakan, P., Nhung, D. T. H., Nakphaichit, M. \& Klangpetch, W. Intensification of cellulolytic hydrolysis of rice husk, rice straw, and defatted rice bran by sodium hydroxide pretreatment. FAB J. 7, 172-183 (2019).

31. Prommadee, P., Garnjanagoonchorn, W., de Lange, K. \& Nitisinprasert, S. Characterization of Lactobacillus johnsonii KUNN19-2 and Pediococcus pentosaceus KUNNE6-1 isolated from thai-style fermented pork (Nham) for their probiotic properties in the gastrointestinal tract and immunomodulation. Agric. Nat. Resour. 46, 440-450 (2012).

32. Sobanbua, S. et al. Cloning and expression of the antimicrobial peptide from Lactobacillus reuteri KUB-AC5 and its characterization. Technology 16, 1013-1036 (2020).

33. Plupjeen, S. N., Chawjiraphan, W., Charoensiddhi, S., Nitisinprasert, S. \& Nakphaichit, M. Lactococcus lactis KA-FF 1-4 reduces vancomycin-resistant enterococci and impacts the human gut microbiome. 3 Biotech 10, 1-11 (2020).

34. Nakphaichit, M. et al. The effect of including Lactobacillus reuteri KUB-AC5 during post-hatch feeding on the growth and ileum microbiota of broiler chickens. Poult. Sci. 90, 2753-2765 (2011).

35. Minekus, M. et al. A standardised static in vitro digestion method suitable for food-an international consensus. Food Func. 5, 1113-1124 (2014).

36. Korakli, M., Gänzle, M. G. \& Vogel, R. F. Metabolism by bifidobacteria and lactic acid bacteria of polysaccharides from wheat and rye, and exopolysaccharides produced by Lactobacillus sanfranciscensis. J. Appl. Microbiol. 92, 958-965 (2002).

37. Ismail, M. S. \& Waliuddin, A. M. Effect of rice husk ash on high strength concrete. Constr. Build. Mater. 10, 521-526 (1996).

38. Di Blasi, C., Signorelli, G., Di Russo, C. \& Rea, G. Product distribution from pyrolysis of wood and agricultural residues. Ind. Eng. Chem. Res. 38, 2216-2224 (1999).

39. Garrote, G. D. H. P., Dominguez, H. \& Parajo, J. C. Hydrothermal processing of lignocellulosic materials. Holz als roh-und werkstoff 57, 191-202 (1999).

40. Vegas, R., Alonso, J. L., Domínguez, H. \& Parajó, J. C. Processing of rice husk autohydrolysis liquors for obtaining food ingredients. J. Agric. Food Chem. 52, 7311-7317 (2004).

41. Desai, M. S. et al. A dietary fiber-deprived gut microbiota degrades the colonic mucus barrier and enhances pathogen susceptibility. Cell 167, 1339-1353 (2016).

42. Harmsen, P. F., Huijgen, W., Bermudez, L. \& Bakker, R. Literature review of physical and chemical pretreatment processes for lignocellulosic biomass (No. 1184). Wageningen UR-Food \& Biobased Research (2010).

43. Brienzo, M., Carvalho, W. \& Milagres, A. M. Xylooligosaccharides production from alkali-pretreated sugarcane bagasse using xylanases from Thermoascus aurantiacus. Appl. Biochem. Biotechnol. 162, 1195-1205 (2010).

44. Bastos, R., Coelho, E. \& Coimbra, M. A. Arabinoxylans from cereal by-products: Insights into structural features, recovery, and applications. In: Sustainable Recovery and Reutilization of Cereal Processing By-Products 227-251 (Woodhead Publishing, 2018).

45. Chen, W. H., Tu, Y. J. \& Sheen, H. K. Disruption of sugarcane bagasse lignocellulosic structure by means of dilute sulfuric acid pretreatment with microwave-assisted heating. Appl. Energy 88, 2726-2734 (2011).

46. Lafond, M., Guais, O., Maestracci, M., Bonnin, E. \& Giardina, T. Four GH11 xylanases from the xylanolytic fungus Talaromyces versatilis act differently on (arabino) xylans. Appl. Microbiol. Biotechnol. 98, 6339-6352 (2014).

47. Ethaib, S., Omar, R., Kamal, S. M. \& Biak, D. A. Microwave-assisted pretreatment of lignocellulosic biomass: A review. J. Eng. Sci. Technol. 10, 97-109 (2015).

48. Diaz, A. B. et al. Evaluation of microwave-assisted pretreatment of lignocellulosic biomass immersed in alkaline glycerol for fermentable sugars production. Bioresour. Technol. 185, 316-323 (2015).

49. López-Linares, J. C., Lucas, S., García-Cubero, M. T., Jiménez, J. J. \& Coca, M. A biorefinery based on brewers spent grains: Arabinoxylans recovery by microwave assisted pretreatment integrated with butanol production. Ind. Crops Prod. 158, 113044 (2020).

50. Puligundla, P., Oh, S. E. \& Mok, C. Microwave-assisted pretreatment technologies for the conversion of lignocellulosic biomass to sugars and ethanol: A review. Carbon Lett. 17, 1-10 (2016).

51. Kim, J. S., Lee, Y. Y. \& Kim, T. H. A review on alkaline pretreatment technology for bioconversion of lignocellulosic biomass. Bioresour. Technol. 199, 42-48 (2016).

52. Binod, P. et al. Short duration microwave assisted pretreatment enhances the enzymatic saccharification and fermentable sugar yield from sugarcane bagasse. Renew. Energy 37, 109-116 (2012).

53. Belyaev, I. Non-thermal biological effects of microwaves. Microw. Rev. 11, 13-29 (2005).

54. Wang, T. H. \& Lu, S. Production of xylooligosaccharide from wheat bran by microwave assisted enzymatic hydrolysis. Food Chem. 138, 1531-1535 (2013).

55. Roos, A. A., Persson, T., Krawczyk, H., Zacchi, G. \& Stålbrand, H. Extraction of water-soluble hemicelluloses from barley husks. Bioresour. Technol. 100, 763-769 (2009).

56. Jiang, Y. et al. Optimization of ultrasonic-microwave assisted alkali extraction of arabinoxylan from the corn bran using response surface methodology. Int. J. Biol. Macromol. 128, 452-458 (2019).

57. Collins, T., Gerday, C. \& Feller, G. Xylanases, xylanase families and extremophilic xylanases. FEMS Microbiol. Rev. 29, 3-23 (2005).

58. Cheng, Y. S. et al. Structural analysis of a glycoside hydrolase family 11 xylanase from Neocallimastix patriciarum: Insights into the molecular basis of a thermophilic enzyme. J. Biol. Chem. 289, 11020-11028 (2014).

59. Morgan, N. K., Wallace, A., Bedford, M. R. \& Choct, M. Efficiency of xylanases from families 10 and 11 in production of xylooligosaccharides from wheat arabinoxylans. Carbohydr. Polym. 167, 290-296 (2017).

60. Ataei, D., Hamidi-Esfahani, Z. \& Ahmadi-Gavlighi, H. Enzymatic production of xylooligosaccharide from date (Phoenix dactylifera L.) seed. Food Sci. Nutr. 8, 6699-6707 (2020).

61. Falk, P. et al. Production of arabinoxylan-oligosaccharide mixtures of varying composition from rye bran by a combination of process conditions and type of xylanase. Bioresour. Technol. 174, 118-125 (2014).

62. Roberfroid, M. B. Prebiotics: Concept, Definition, Criteria, Methodologies, and Products 39-69 (CRC Press, 2008).

63. Neyrinck, A. M. et al. Wheat-derived arabinoxylan oligosaccharides with prebiotic effect increase satietogenic gut peptides and reduce metabolic endotoxemia in diet-induced obese mice. Nutr. Diabetes 2, e28-e28 (2012).

64. Kim, J. H., Shoemaker, S. P. \& Mills, D. A. Relaxed control of sugar utilization in Lactobacillus brevis. Microbiology 155, 1351-1359 (2009).

65. Kariyawasam, K. M. G. M. M., Lee, N. K. \& Paik, H. D. Synbiotic yoghurt supplemented with novel probiotic Lactobacillus brevis KU200019 and fructooligosaccharides. Food Biosci. 39, 100835 (2021).

66. Moura, P. et al. In vitro fermentation of xylo-oligosaccharides from corn cobs autohydrolysis by Bifidobacterium and Lactobacillus strains. LWT 40, 963-972 (2007).

67. Iliev, I., Vasileva, T., Bivolarski, V., Momchilova, A. \& Ivanova, I. Metabolic profiling of xylooligosaccharides by lactobacilli. Polymers 12, 2387 (2020).

68. Boron, W. F. \& Boulpaep, E. L. Medical Physiology, 2e Updated Edition E-Book: With Student Consult Online Access (Elsevier Health Sciences, 2012). 
69. de Figueiredo, F. C., de Barros Ranke, F. F. \& de Oliva-Neto, P. Evaluation of xylooligosaccharides and fructooligosaccharides on digestive enzymes hydrolysis and as a nutrient for different probiotics and Salmonella typhimurium. Lwt 118, 108761 (2020).

70. Roberfroid, M. Dietary fiber, inulin, and oligofructose: A review comparing their physiological effects. Crit. Rev. Food Sci. Nutr. 33, 103-148 (1993).

71. Janeček, Š, Svensson, B. \& MacGregor, E. A. a-Amylase: An enzyme specificity found in various families of glycoside hydrolases. Cell. Mol. Life Sci. 71, 1149-1170 (2014).

\section{Acknowledgements}

This research was financially supported by the Thailand Research Fund (MRG6180290) and partially supported by Chiang Mai University.

\section{Author contributions}

W.K.: Supervision, Conceptualization, Methodology, Writing-original draft, Writing—review and editing, Project administration, Funding acquisition. A.P.: Investigation, Methodology, Visualization, Writing-review and editing. S.P.: Resources. N.U.: Methodology. T.L.: Investigation. P.T.: Methodology. T.I.W.: Writing-review and editing. P.J.: Investigation, Methodology.

\section{Competing interests}

The authors declare no competing interests.

\section{Additional information}

Supplementary Information The online version contains supplementary material available at https://doi.org/ 10.1038/s41598-021-03360-2.

Correspondence and requests for materials should be addressed to W.K.

Reprints and permissions information is available at www.nature.com/reprints.

Publisher's note Springer Nature remains neutral with regard to jurisdictional claims in published maps and institutional affiliations.

(c) (i) Open Access This article is licensed under a Creative Commons Attribution 4.0 International License, which permits use, sharing, adaptation, distribution and reproduction in any medium or format, as long as you give appropriate credit to the original author(s) and the source, provide a link to the Creative Commons licence, and indicate if changes were made. The images or other third party material in this article are included in the article's Creative Commons licence, unless indicated otherwise in a credit line to the material. If material is not included in the article's Creative Commons licence and your intended use is not permitted by statutory regulation or exceeds the permitted use, you will need to obtain permission directly from the copyright holder. To view a copy of this licence, visit http://creativecommons.org/licenses/by/4.0/.

(C) The Author(s) 2022, corrected publication 2022 